\title{
Musicoterapia, en sintonía al final de la vida
}

\author{
Mireia Serra VILA ${ }^{1}$ \\ mireia.serravila@gmail.com
}

Recibido: 8-6-15

Aceptado: $30-9-15$

\section{Resumen}

En este artículo se muestra la musicoterapia como elemento de apoyo a la persona (y su familia) que vive el final de su vida. También como terapia no farmacológica y complementaria en una medicina integral, holística. Lo aquí expresado surge de la experiencia directa, de sesiones y reflexiones realizadas a lo largo de los años en unidades de oncología y cuidados paliativos. Hablamos de silencio, música, terapia, modelos y técnicas, leeremos y sentiremos sesiones... pero hablamos, sobre todo, de vida, conciencia y amor.

Palabras clave: Musicoterapia; cuidados paliativos; vida; espiritualidad.

\section{Music therapy, in tuning at the end of life}

\begin{abstract}
In this article music therapy is presented as a helpful tool to support the persons (and their relatives) living at the end of their life and, also, as a non pharmacological and complementary therapy in an integral and holistic medicine. What we report here comes from the direct experience, nourished after many years of interventions and reflections in oncology and palliative care units. We're talking about silence, music, therapy, models and techniques. We will read and feel therapeutic sessions... but above all, we're talking about life, conscience and love.
\end{abstract}

Key words: Music therapy; palliative care; life; spirituality.

\section{Sumario}

Silencio. El sonido, la música. Musicoterapia. Vínculo. Acompañamiento. Vida. Modelos / Evaluación. Creación. Expresión. "Mi Familia”. Trascendencia, Espiritualidad. Transformación. Esperanza. Gozo. Respiración. Gratitud.

\section{Introducción}

La música, con los elementos que la componen (sonido, ritmo, melodía y armonía) es un lenguaje no verbal, universal. 
El texto que se ofrece a continuación es fruto de la experiencia y la reflexión como persona y musicoterapeuta a lo largo de más de diez años de dedicación en las unidades de oncología médica y cuidados paliativos de diferentes hospitales de España.

En ámbito médico, desde su vertiente terapéutica, integrada en un equipo interdisciplinar puede ayudar en el diagnóstico, el tratamiento, la comunicación (verbal y no verbal) y la prevención (Dileo, 1997)

En momentos de final de vida, la música puede ser una herramienta de apoyo a pacientes y sus familiares para atender las necesidades físicas, sociales, emocionales y espirituales que surjan a lo largo de este proceso. Se crea en el aquí y ahora, a medida. A veces la música llega donde no llegan las palabras.

A través de pequeños apartados, a modo de ventanas, veremos discurrir delante de nosotros palabras, frases, títulos de canciones, escenas de sesiones,... que nos permitirán entender los objetivos, la metodología, el tiempo de acompañamiento, también la dificultad de la evaluación... de la musicoterapia al final de la vida. Un elemento tangible y a la vez sutil, para un gran misterio.

\section{(Silencio)}

Silencio. Nada. Atención. Concentración. Respiración. Latido.

El silencio nos da espacio para respirar, y permiso para entrar en la música. Es desde el silencio que surge el sonido, la creación. Desde nuestro interior.

Encontramos silencio antes, durante y después de la música. Antes, para crear. Durante, para respirar, digerir, articular, hacer una pausa y seguir. Después, para integrar.

No tenemos constancia, registro sonoro del silencio. Podemos imaginarlo con algunas imágenes. "Si el silencio es sonido, Buda es un maestro", nos dice Stevens (2014: 182). Las esculturas y pinturas de Buda lo representan en actitud de silencio, postura serena, boca cerrada y grandes orejas.

Lo importante es sentirlo. Serenamente, en paz. ...Respira.... Toma aire.... empezamos.

\section{El sonido, la música}

“Qué es la música? Lo que no se oye... Cuanto más hagamos valer en ella lo que no se oye y cuanto más utilicemos lo audible para hacer valer lo inaudible, tanto más llena de alma estará la música...”

(Wünsch, 1995: 25)

Un sonido, luego dos... otro que se añade... sonidos que se combinan, que juegan, alternan, se juntan, separan... El sonido llega, penetra y afecta todo nuestro ser. (Inayat, 1995).

La relación entre estos sonidos, notas, intervalos, es música. La vida está llena de música. Los componentes que la conforman (ritmo, melodía, armonía...) se cruzan con nosotros continuamente, a veces de manera sutil (el ciclo de las estaciones, el 
latido del corazón, un tarareo), a veces de manera más evidente. En todos los casos nos afectan: el ritmo, a nivel fisiológico; la melodía, a nivel emocional, y la armonía, a nivel mental (modelo Willems, en Del Campo, 1997). Somos seres rítmicos y tonales. (Hartley, 1999).

$\mathrm{Su}$ organización, expresión y percepción varían también según la cultura. Se establece, pues, la música como un producto humano, cultural, destinado a suscitar una experiencia estética y generar sentimientos.

Quizá no somos conscientes de cómo la música llega y forma parte de nuestra vida, pero todos tenemos músicas, voces, canciones, títulos, situaciones (fragmentos de conciertos, ensayos, escenas familiares...), momentos inolvidables (positivos o negativos) que forman parte de nuestra trayectoria vital. Momentos únicos. Momentos vitales.

\section{Musicoterapia}

La literatura nos ofrece cada vez más revisiones e investigaciones sistemáticas de musicoterapia en cuidados paliativos, tanto en población adulta como pediátrica, que muestran los beneficios de esta terapia complementaria no farmacológica. (Bradt \& Dileo, 2010, Hanser, 2006; Hilliard, 2005, 2006; Serra et al., 2014)

En el ámbito de oncología y paliativos, la podemos describir como el uso profesionalmente informado y creativo de la música, dentro de una relación terapéutica con la persona identificada que necesita ayuda psicosocial, física o espiritual, o que desea conocerse más a sí misma, permitiendo mejorar su calidad de vida (O'Callaghan, 2009). Esto lo concretamos en algunos objetivos terapéuticos, a trabajar con el paciente y/o cuidador, y que pueden ser: reducir la percepción del dolor, la ansiedad y la depresión; mejorar el estado de ánimo, distraer; relajar, facilitar la comunicación y la expresión emocional; facilitar herramientas de afrontamiento y aceptación; evocar; ofrecer apoyo para decir adiós, conectar con la parte espiritual de la persona, acompañar hasta el final y facilitar el proceso de duelo (Serra et al., 2014).

La definición la completamos con otro aspecto, la rigurosidad, defendida por la World Federation of Music Therapy (WFMT) en su página web (2011): "la investigación, la práctica, la educación y la instrucción clínica en la musicoterapia están basadas en estándares profesionales según los contextos culturales, sociales y políticos".

\section{Vínculo}

Los sonidos, igual que los colores, no existen, no se producen, si no hay nadie que los perciba, que los escuche. (Duran, 2006.). Somos emisores y receptores de señales. Somos seres sociales.

La comunicación humana va más allá del lenguaje verbal, es predominantemente no verbal (casi un $80 \%$ ). Una parte de ella es sonora. Cada vez que hay un cambio en alguna secuencia sonora se activa una respuesta. Desde que nacemos, las interacciones vocales madre-bebé, basadas en series armónicas y pentatónicas, expresan comunicación y vínculo (Puyvelde, 2010). El bebé puede apoyarse 
afectivamente y reposar, pues la música le ha transmitido seguridad y sensación de compañía. Le permite también proyectarse.

Esta interacción de la persona con su entorno sonoro se extiende a lo largo de toda su vida, favoreciendo los vínculos entre personas y las redes sociales (Serra, 2013). Si consideramos el curso de la vida, incluyendo el morir como proceso de desarrollo (Aldridge, 1995), constatamos que a medida que la enfermedad avanza y la capacidad de comunicación verbal disminuye, el uso de la música como recurso terapéutico adquiere especial significado. Recibimos información por los cinco sentidos. Los cuidadores evidencian la importancia de la postura, el gesto, el rostro, el contacto visual, el tacto y el sonido como forma de comunicación y expresión. (Serra et al., 2014).

¿Por qué es importante para el paciente tocar/hacer música con nosotros? (Hartley, 1999: 117)

Siguiendo a Campbell (1997), músico y oyente (musicoterapeuta/paciente -en nuestro caso), parten de un lugar y lenguaje común, desde donde pueden iniciar y cimentar una confianza, expresión y paz entre ellos.

\section{Acompañamiento}

Entre las acepciones que la Real Academia muestra para la palabra Acompañamiento leemos las siguientes: (RAE, 2014)

- "Gente que va acompañando a alguien".

- "Arte de la armonía aplicado a la ejecución del bajo continuo".

En tiempos antiguos, cuando alguien preguntaba por el camino en el desierto, era responsabilidad de la persona a quien habían pedido ayuda hacer parte del camino con ella. Caminaba junto a ella hasta estar seguro que la persona iba en dirección correcta. Así también en terapia. Andamos junto los que nos vienen a pedir ayuda... Y lo experimentamos al trabajar con el morir. (Aldridge, 1999)

Desde la presencia, la música, escuchamos, esperamos, experimentamos y nos ajustamos a la realidad de la persona que viene y acogemos. (Campbell, 1997). Desde ese bajo continuo que mantiene y sostiene hasta llegar al destino. Y proporcionando un sentimiento de cierre o conclusión.

Esta realidad observada puede ser muy diversa. En nuestros objetivos podemos intervenir para distraer y crear un momento único y lúdico para toda la familia, rebajar tensión durante la comida, distraer para reducir la percepción del dolor durante un aseo o proceso doloroso (una cura), acompañar a los agentes de pastoral en un momento de oración y recogimiento, evocar un lugar significativo y un momento de paz para el paciente, encauzar una respiración agitada...

El pie de cama, junto a pacientes y cuidadores, es el lugar, el setting desde donde interviene el musicoterapeuta. Un espacio que favorece y refuerza este vínculo.

La música es en directo, con los instrumentos adecuados, que actúan de objeto intermediario (guitarra, arpa, voz, flauta, ... instrumentos melódicos y de pequeña percusión - panderos y panderetas, sonajeros, castañuelas, kalimba, palo de lluvia, ocean drum..). El estilo musical, el de preferencia o significativo para la persona. 
También es la persona quien determina el tiempo de acompañamiento, marcándonos el inicio y el final de la sesión. Pequeños diálogos y signos sencillos, muy íntimos, nos indican cómo gestionar el tiempo (a través de unos párpados que se cansan o un destello chispeante, un pequeño giro en la mano hacia arriba o abajo, un suspiro, una sonrisa, una palabra...). Podemos acompañar durante minutos o casi una hora, sintiendo y adaptándonos a la necesidad. También sabemos que, en una unidad donde el tiempo cobra tanta importancia, la música cambia como la percepción de éste. Vivimos un tiempo rico en calidad, intenso, más allá del tiempo cronológico.

\section{Vida}

¿Qué canciones / músicas nos conectan con la vida y el amor?Trabajamos con personas al final de su vida, que anhelan que las tratemos como a personas vivas y no como enfermedades. (Rimpoché, 2006)

En primer lugar trataremos el dolor, lo tendremos en cuenta y paliaremos desde todos los ámbitos, desde un equipo interdisciplinar que apoya en todo momento esta delicada travesía.

En segundo lugar, desde el presente continuo, sintiendo la vida. Pacientes y cuidadores viven grandes momentos de transformación, que requieren adaptación continua a un proceso cambiante.

En esta revisión necesaria de vida, la música permite recordar, sentir y anclar momentos muy significativos, que nos conectan a la vida y el amor. Como si reuniéramos pequeñas joyas de un collar muy preciado, que guardamos en nuestro interior, pero elaborado entre todos.

Y finalmente, nosotros, como terapeutas, debemos trabajar desde nuestra conexión con la vida, desde la conciencia, desde el trabajo interno hecho previo sobre nuestro miedo/impulso o enganche a morir/vivir.

Kearney (2012) recomienda cultivar y practicar en nosotros un "uso terapéutico del self" que atienda nuestras profundidades internas, y aquello que en nosotros no tiene miedo a la muerte. E intervenir desde allí, el no miedo. Esto es sólo posible si somos autoconscientes y estamos conectados (grounded).

Solo reconociendo, acogiendo y trascendiendo nuestros miedos, desde la plena conciencia, la vida y el amor, podemos ofrecer un buen acompañamiento.

"¿Y qué es la vida? La vida es amor. Y, ¿qué es el amor? El amor es Dios" (Inayat, 1995: 116)

\section{Modelos / Evaluación}

Enmarcar el trabajo que realizamos con musicoterapia en un modelo y sistema de evaluación no resulta fácil. Creo importante aportar datos que la literatura científica nos ofrece, mostrar modelos y cuestionarios que profundizan en aspectos tan sutiles como la espiritualidad, sin olvidar los elementos musicales, ellos mismos agentes de cambio.

La literatura científica enfoca, por una parte, aspectos como la utilidad de la musicoterapia (en pacientes, seres queridos, equipo) y los resultados de las sesiones 
y, por otra parte, aspectos sobre una buena práctica clínica (Lingard et al, en O’Callaghan, 2009).

Los estudios controlados aleatorizados que consiguen resultados significativos con musicoterapia indican una mejoría en humor, calidad de vida, relajación, confort, felicidad, presión sanguínea diastólica, y una reducción en cuanto a estrés, frecuencia cardíaca, dolor, depresión, ansiedad y miedo (O’Callaghan, 2009):

Una revisión Cochrane de 51 estudios y 3.663 sujetos evalúa la eficacia de la musicoterapia al final de la vida sobre respuestas fisiológicas, psicológicas y sociales. Los datos indican un posible beneficio en la calidad de vida, poca evidencia fuerte en la percepción de dolor y ansiedad; diferencia significativa en el dolor con música en directo frente a música grabada; reducción de la necesidad de analgésicos similares a la morfina una hora después y una diferencia significativa en el bienestar post sesión. Aunque el beneficio es pequeño y no es un tratamiento de primera línea, animan a continuar investigando para obtener mayor evidencia (Bradt \& Dileo, 2010).

En esta línea, Serra et al. (2012) mostraron que la musicoterapia reducía la percepción del dolor durante un procedimiento terapéutico doloroso en pacientes de cuidados paliativos, constatando un aumento de saturación de oxígeno y una disminución de la frecuencia cardíaca después de la intervención.

Posteriormente, Serra et al. (2014) valoraron la satisfacción de los cuidadores y los beneficios obtenidos del programa de musicoterapia en una unidad de cuidados paliativos, mediante una encuesta elaborada ad-hoc (con preguntas de tipo abierto y cerrado). El análisis de las 100 encuestas recibidas destacó la percepción de apoyo, participación activa en familia, relajación y bienestar, facilitación de la comunicación, mejora del estado de ánimo, de la percepción del paso del tiempo y conexión con el mundo espiritual.

Precisamente, encontramos modelos y cuestionarios que nos acercan a la valoración de las necesidades espirituales del paciente y del proceso que vive, utilizando varias dimensiones y elementos no únicamente verbales, sino también imágenes y metáforas:

- El Cuestionario del Sentido de la Vida [Meaning in Life ScaleMiLS-Sp], estandarizado y hetero/autoadministrado, propone cuatro dimensiones o escalas de espiritualidad: Propósito de vida; Falta de significado; Paz interior, y Beneficios de la espiritualidad. (Reig-Ferrer et al. 2015).

- La muerte como transición. Entender la muerte como una transición puede ayudar a reinterpretar aquello que el paciente necesita. Esta transición se desarrolla en tres fases fenomenológicamente distintas: pre-transición, transición y post-transición/apertura espiritual. El modelo abraza dimensiones no verbales. En la pre-transición, puede darse una sensibilidad auditiva creciente, signo que presagia una transición que progresa. En la última, post-transición, muchos pacientes no pueden hablar, pero todavía oyen. La comunicación es mayoritariamente no verbal. La transición, como en el nacimiento, ocurre en horas, más que en días (Renz et al., 2013).

- Modelo del cuidado del alma. De acuerdo a lo mencionado anteriormente, el modelo propone partir de nuestro interno profundo que no tiene miedo a la 
muerte. Usando la metáfora de la ola en el mar, se visualizaría como el agua del fondo (nuestro ser más interno y el colectivo), que siempre está tranquila, aunque en la superficie la ola (el ego) se mueva, desplace, se estremezca... (Kearney et al., 2012)

- Cuestionario del Grupo de Espiritualidad de la Sociedad Española de Cuidados Paliativos (SECPAL). Cuestionario de 8 ítems, que pregunta a la persona por tres dimensiones: intrapersonal - interpersonal - transpersonal (Galiana et al., 2014)

En la práctica diaria musicoterapéutica, los títulos y el carácter de las improvisaciones musicales, las canciones que se componen, la calidad e intensidad de la voz, los instrumentos escogidos..., nos acercan a este mundo sutil y espiritual, de paz, de conexión con esta realidad superior. En relación al cuestionario anterior, por ejemplo, los elementos especialmente relevantes y que aparecen en la práctica musicoterapéutica pueden relacionarse con los siguientes ítems: $\mathrm{n}^{\circ} 5$ : Interpersonal ("Me siento en paz y reconciliado con los demás") y n $\mathrm{n}^{\circ}$ : Transpersonal ("Me siento conectado con una realidad superior: la naturaleza, Dios,...").

Los modelos de musicoterapia también tienen sus elementos propios de evaluación, con escalas dirigidas tanto a producción musical como a interacción entre paciente y terapeuta (Bruscia, 1999):

- Modelo de Musicoterapia creativa o humanista, Nordoff-Robbins. Uno de los cinco modelos reconocidos oficialmente por la WFMT. El modelo reconoce la persona como un ser musical, creativo; se centra en atender los recursos y potenciales que se preservan; la música se crea en directo, a partir del estado de ánimo y su percepción sobre ella; la persona se identifica en la música y emerge en esta música, dotándola de su propio significado interno y favoreciendo emociones positivas.

- Las 64 técnicas de improvisación de Bruscia nos ayudan a acompañar en esta travesía. Con la música como vehículo, podemos usarlas para dar estructura, crear empatía, ofrecer intimidad, facilitar, redirigir, explorar a nivel emocional...

Esta complejidad y, a la vez, riqueza de herramientas, modelos y evaluaciones, nos permiten acoger y valorar la persona en su globalidad, en todos sus ámbitos. Caminando juntos.

\section{Creación}

"Incluso en medio del sufrimiento es posible crear algo bello"

(Aldridge, 1999: 20)

Al hacer música en el aquí y ahora nos inventamos, reinventamos, nos creamos una nueva identidad, desde donde podemos trascender el sufrimiento. En el sentido inmaterial, como hacer música, la creatividad ayuda a superar el momento. En esta 
creatividad trascendemos, saltamos hacia la esperanza en un nuevo conocimiento. Actualizar todo aquello que queda en nosotros, incluso cuando el elemento material de vida corporal se descompone, es un acto creativo. Es una creación estética, no moral, sin juicio (Aldridge, 1999).

Y de esta manera, en verdad, podemos entender el proceso dinámico improvisado de "musicking" (hacer/tocar música) como un proceso de "healthing" (bienestar, sanación) (Aldridge, 2003).

\section{Expresión}

"Sarandonga, esto es lo que te quiero decir"

La música será el objeto intermediario, el elemento facilitador del cambio. Para ello, el musicoterapeuta debe crear una estructura musical en la cual el paciente se encuentre seguro, cómodo y con confianza para poder desarrollar una relación terapéutica que facilite la apertura hacia el exterior y la consecución de los objetivos marcados, transformación de hábitos, simbolización... (Bageneta, 1997, en Serra, 2013).

Improvisar con la voz o los instrumentos, tocar, escuchar, cantar, analizar la letra o componer canciones; visualización con música, música y movimiento... son algunas de las técnicas que utilizamos y nos permiten comunicar y expresar.

Cuando el paciente todavía se puede expresar verbalmente, escuchar y componer canciones (songwriting) es una forma poderosa de identificar emociones espontáneamente, expresarse, explicar historias, evitando así procesos de pensamiento concretos y mecanismos de defensa (Heath et al., 2012; Tamplin, 2006).

Las canciones dan voz a palabras que a veces son difíciles de articular. Pueden formar parte de su historia musical, adquieren importancia y significación en ese momento por su letra, su simbolismo, melodía, sentimiento a expresar, oración.... También podemos crearlas en directo. Si la canción contiene las palabras y música propuestas por el paciente, si es grabada en directo, con su propia voz... esto proporciona un material, un legado que es a la vez profundo y único (Heath et al., 2012).

O'Callaghan (1996) registró los usos que podían tener las canciones compuestas por los pacientes: dar mensajes; hacer autorreflexiones, agradecimientos (familia, equipo, Dios...); sacar recuerdos relacionados con gente (viva o muerta); reflexionar sobre otros seres significativos (incluyendo mascotas); expresar la adversidad; desarrollar la imaginería (descripción de imágenes y lugares de la naturaleza), sentir sobre la existencia en el futuro, y orar.

También recogió la temática y en qué momento o fase podían emerger (esperanza, placer, el mundo, recuerdos, relaciones, necesidades y deseos, sentimientos, pérdida y muerte y paz).

Un ejemplo del uso de la canción como medio de expresión emocional y legado es el que ofrecemos a continuación. 


\section{"Mi Familia"}

Este es el título del CD que una paciente decide grabar para su familia. Contiene varias pistas: palabras que les dirige directamente, canciones de cantantes conocidos que identifica con sus seres queridos y una canción, grabada en la unidad. Esta canción parte de una melodía conocida y propuesta por la paciente, a la que le cambia la letra a lo largo de una sesión. Contiene varias estrofas, una para cada integrante de su familia. Se exponen aquí el estribillo, la estrofa dedicada y la estrofa final (en su versión original, pues está de acuerdo con su contenido y no cree necesario cambiarlo).

Sarandonga, esto es lo que te quiero decir

Sarandonga, que me voy pa'l otro lao

Sarandonga, a lo alto del cielo

Sarandonga, a comer el bacalao

Sarandonga, que chíviri que chíviri

Sarandonga, que chíviri que chíviri

Sarandonga, que chíviri que chíviri

Sarandonga, y óyeme cantar.

....

A mi nuera Rosana, yo le quería decir

Agradezco lo que has hecho, lo que has hecho tú por mí

Que te quiero con locura, ay, ay que me duele aquí.

Sarandonga, esto es lo que te voy a decir...

Esta vida hay que beberla en sorbitos de cristal

Esta vida hay que beberla en sorbitos de cristal

Un sorbito por nosotros y otro por los que no están.

Sarandonga, esto es lo que te voy a decir...

\section{Trascendencia, Espiritualidad}

"Porque es al dar cuando se recibe"

(San Francisco de Asís -en Rimpoché, 2006: 451)

Desde la musicoterapia se realza la espiritualidad facilitando cuatro aspectos primarios: trascendencia, fe y esperanza, sentido de significado, y objetivo y conexión. (McClean et al., 2012)

La transcendencia es un "ir más allá", a otro nivel de comprensión y conciencia. Está basado sobre una capacidad innata que tenemos como seres humanos para sobrepasar la situación (Aldridge, 2003). También es una conexión entre las personas, los otros y el más allá, en una idea de establecer la vida más allá de uno mismo, una continuidad. (Serra et al., 2014)

La espiritualidad presta el significado y el objetivo a nuestras vidas, estos objetivos nos ayudan a superar lo que somos (Aldridge, 2003). 


\section{Transformación}

Mencionamos un estudio recién publicado con 251 pacientes con cáncer avanzado (Renz et al., 2015), observados durante 12 meses por un psico-oncólogo/ musicoterapeuta. De ellos, 135 comunicaron una experiencia espiritual, expresada por una mejor conciencia corporal y un sentido alterado del "aquí y ahora", la mayor parte espontáneamente. Son experiencias personales e íntimas. En cuanto a su presencia, parecen anunciar la muerte o facilitar el proceso de muerte. Van asociadas con profundas y poderosas reacciones (físicas, psicológicas, espirituales) que alivian el sufrimiento, como son reducción de dolor, a veces menos disnea, menor ansiedad, mayor aceptación y actitud diferente ante la enfermedad, la vida, la muerte y Dios/lo divino; una nueva identidad espiritual. Pero también hay un remarcable número de pacientes con experiencias espirituales dificultosas.

Quizás hay una diferencia entre la actitud espiritual de los pacientes y aquello que experimentan. Es notable que las experiencias espirituales se observan en pacientes con varias actitudes/afiliaciones religiosas, con o sin experiencias espirituales previas.

Estos autores animan también a ahondar en los casos de Experiencia Cercana a la Muerte (ECM) para entender este fenómeno. Siguiendo a Van Lommel (2012), las personas que han pasado por una ECM y la han podido expresar, afirman un cambio de opinión sobre sus prioridades en la vida, lo que realmente importa, y han perdido el miedo a la muerte. En relación a la música, los datos aportados por Van Lommel afirman que un $10 \%$ de los pacientes comenta haber accedido a otra dimensión, de increíble belleza, en la que oye una música preciosa.

En cuanto a la relevancia clínica, Renz et al. (2015), concluyen que el modelo de cuidado basado en la experiencia espiritual puede complementar al basado en las necesidades.

En todo caso, toca asumir que el proceso de la muerte es normal, un hecho biológico, humano, social y espiritual, que ofrece una oportunidad para descubrir nuestra naturaleza espiritual y crecer y madurar (Galiana et al., 2014).

\section{Esperanza}

"Ábreme la puerta, que vuelvo a Tánger" (Palabras pronunciadas por un paciente al oír el ocean drum -tambor de océano)

Tema de reflexión que aparece (después de la alegría y los recuerdos pasados) cuando los cuidadores consideran el futuro y los pensamientos asociados a la esperanza.

Implica pensamientos y sentimientos, y requiere acción. Es dinámica, como la música, y susceptible a la influencia humana. Nos inclina hacia algo que no sabemos (Aldridge, 1995) y a un poder interior dirigido al enriquecimiento del ser (Heath, 1990; Magill, 2009). Simboliza resultados futuros y personales que pueden hacerse cada vez más importantes para el individuo, como "ampliar o revitalizar intereses, ampliación del self hacia otros, y cambiar la perspectiva personal" (Tanyi, en McClean et al., 2012: 403). 


\section{Gozo}

El mantra de los Prajnaparamita: "Vamos, vamos, vamos más allá, vamos a la otra orilla. ;Iluminación! ;Gozo!”. (Nhat Hanh, 2007: 158)

Transcripción de una parte de la sesión realizada por una paciente de una Unidad de Cuidados Paliativos, mientras improvisa con el arpa sin apenas parar, acompañada por esta musicoterapeuta. Parte de la sesión puede ser vista a través del enlace al documental mencionado en la bibliografía. Se anotan en corchetes las palabras de la sesión que no fueron incluidas en el documental (Serra et al., 2008: 87-88; TVE):

"Como si me bañara en el agua, como si me introdujera en el agua... es como si nadara... los olmos, las choperas... todo vuela, los animales vuelan, están bien, felices.

- ¿Y tú cómo estás, aquí en el agua? -pregunta la musicoterapeuta.

- Muy bien, contemplándolo todo y... Era un río mágico, tenía mucha agua que corría, pero flojita, suave. Es que a mí me gusta mucho el agua, el río... hacía un deporte de piragüismo y... me acuerdo mucho del ruido del agua, la barca.... Si tuviera que hacer una música para relajarme pues empezaría (sigue tocando)...."

Durante la improvisación, encuentra turbulencias. Apoyamos y expresamos musicalmente la turbulencia, la exploramos, permanecemos en ella unos momentos y la aceptamos como parte de la fluidez del río de su vida. Entra y sale de su turbulencia. Le da significado:

["- Me siento bien, dominándola (la barca) para que no caiga y ese dominio me hace resistente".]

Y regresa al punto de origen, el río vuelve a ser ancho y tranquilo. Mientras remonta el río, describe la belleza del paisaje y de la vida desde una mirada trascendida:

["- Vamos subiendo río arriba hacia desembocar... las plantas, los animales, los olmos... los vemos de otra manera, con otra perspectiva y ves cosas que antes no las has visto y ahora las puedes ver... ya voy llegando... pronto pararé en el sitio para dejarla (la barca)... ya llego, ya llego, ya llego con ganas... y ya bajo.] Aquí deja el arpa, su objeto intermediario.

"Hemos hecho una salida que ha sido muy gratificante porque mentalmente te ayuda mucho a resistir, a aguantar todo, pero con felicidad., no con amargura ni drama"

En sus últimos días, la paciente solicita ver de nuevo la grabación, ahora acompañada por su marido. Éste, durante estos días, la visualizará también con sus amigos en casa. Las imágenes, las palabras hablan por sí solas, sirven para aceptar y despedirse. Una vez fallecida la paciente, las cenizas se arrojarán en la parte del río descrito durante la sesión.

Con sus palabras y vídeo, se cumple así su deseo de dejar un legado y que su experiencia sirva para mostrar la culminación de la vida con gozo. 


\title{
Respiración
}

El cuerpo se debilita, la enfermedad avanza, la respiración se enlentece...

El cuerpo, el mundo kinésico, vincula quietud y silencio. Son dos pilares de la cultura, frecuentes en la vida cotidiana (Poyatos, en Mateu, 2001). Tan frecuentes, como es nuestra respiración.

Parece que la respiración puede ser un instrumento de silencio dentro de nosotros (Stevens, 2014), pero para los musicoterapeutas, la respiración, la frecuencia respiratoria, se convierte en nuestro pulso musical. Empatizamos con el paciente desde su respiración. Él nos dirige. La batuta, sus pulmones. Observándole, sincronizamos con su ritmo y su tono vital, construyendo la música, la melodía, la armonía, elevando el sonido... y acompañando hasta el final, la quietud, el final de la vida, el silencio (si es necesario).

\section{Gratitud}

Como una ola...

A la vida, por lo vivido, por lo aprendido, lo compartido, lo viajado... como seres que hemos coincidido en una parte del camino. Por la música y los silencios, que articulan la melodía. Por la confianza depositada como personas, cuidadores, profesionales... que nos permite llorar, reír, cantar, gritar, susurrar, tararear, estar en silencio, hablar, acariciar, mirar, respirar en unión. La mayor confianza, dejarnos estar presentes en un momento tan sagrado como el nacer, el morir. Gracias por enseñarnos a valorar cada día más las pequeñas cosas, el vivir en el aquí y ahora, en el estar presente, desde el amor y la máxima conciencia posible.

Vamos acabando. En musicoterapia, las canciones también pueden ser compuestas por los familiares o cuidadores del paciente, a quienes también les resulta difícil poner en palabras su mundo interior. En este caso, la canción es realizada por la hija, dirigida a su madre (paciente). Parte de una canción querida, conocida y cantada durante las sesiones tanto por paciente, hija como nieta.

\author{
Como una ola... (versión de M.) \\ Grabé tu nombre en mi almohada, \\ me hice por ti soñadora, \\ para surcar contigo, las nubes de la ilusión. \\ Fui tan feliz en tus brazos, \\ fui tan feliz con tus cuentos, \\ que el corazón se me abre, cuando lo recuerdo así. \\ Como una ola, yo llegué a tu vida \\ Como una ola, de amor y caricias, \\ mucha ternura, ilusión y sonrisas. \\ Como una ola. \\ Y yo quedé, prendida en tu regazo,
}


con tus canciones, se me quitaba el llanto

Como una ola, yo te recordaré,

a ti, R......

Bajé del cielo una estrella,

en el hueco de mis manos

y la prendi de tu cuello,

cuando te dije "te amo".

Pero al mirarte a tus ojos,

veo la luz que tú despiertas,

tanta ilusión con tus hijos

$Y$ rebosando siempre amor.

Como una ola, yo llegué a tu vida...

Bajé del cielo la luna,

que iluminará mi vida,

cuando me falte tu apoyo

y también tu compañia.

No quiero sentirme sola,

pues hablaremos de ti,

siempre estarás con nosotros

tu corazón queda aquí.

Como una ola, yo llegué a tu vida...

M., 24-4-2014

(Silencio)

\section{Bibliografía}

ALDRIDGE, D. (1995). Spirituality, hope and music therapy in palliative care. The Arts in Psychotherapy, Vol. 22, No. 2, 103-109

ALDRIDGE, D. (1999). Music Therapy in Palliative Care: New Voices. London and Philadelphia, Jessica Kingsley Publishers.

ALDRIDGE, D. (2003). Music therapy and spirituality; A transcendental understanding of suffering. Music Therapy Today. (Recuperado el 28 de abril de 2012 de: http://www.wfmt.info/Musictherapyworld/modules/mmmagazine/ issues/20030218101523/20030218102425/SpiritMTTFeb2003.pdf)

BRADT, J. \& DILEO, C. (2010). Music therapy for end-of-life care. Cochrane Database Syst Rev. 2010 Jan 20; (1): CD007169. DOI: 10.1002/14651858. CD007169.pub2.

BRUSCIA, K. (1999). Modelos de improvisación en musicoterapia. Vitoria, Agruparte Producciones.

CAMPBELL, D.G. (1997). Una historia de sanar con música. En: Del Campo, P. (Coord.). La música como proceso humano. Salamanca, Amarú Ediciones.

DEL CAMPO, P. (1997). Del sonido y el silencio hacia la comunicación. En: Del Campo, P. (Coord.). La música como proceso humano. Salamanca, Amarú Ediciones, 207-216. 
DILEO, C. (1997). El proceso musical en pacientes médicos. En: Del Campo, P. (Coord.). La música como proceso humano. Salamanca, Amarú Ediciones, 245-60.

DURAN, X. (2006). L'artista en el laboratori. Univ. València. València, Edicions Bromera.

GALIANA, L., OLIVER, A. \& BARRETO, P. (2014). Recursos en evaluación y acompañamiento espiritual. Revisión de medidas y presentación del cuestionario GES. En: BENITO, E., BARBERO, J. \& DONES, M. Espiritualidad en clínica. Madrid, SECPAL, Monografías, nº, Cap.11, 131-146.

HANSER, S. (2006). Music therapy in adult oncology: Research issues. Journal of the Society for Integrative Oncology, vol. 4(2), 62-66.

HARTLEY, N.A. (1999). Music Therapists' Personal Reflections on Working with Those Who Are Living with HIV/AIDS. En: Aldridge, D. Music Therapy in Palliative Care: New Voices. London and Philadelphia, Jessica Kingsley Publishers, 105-125.

HEATH, B. \& LINGS, J. (2012). Creative songwriting in therapy at the end of life and in bereavement. Mortality: Promoting the interdisciplinary study of death and dying, 17:2, 106-118. http://dx.doi.org/10.1080/13576275.2012.673381.

HILLIARD, R.E. (2005). Music therapy in hospice and palliative care: a review of the empirical data. Evidence-based Complementary and Alternative Medicine, 2(1), 173-178.

HILLIARD, R.E. (2006). Music therapy in pediatric oncology: a review of the literature. J Soc Integr Oncol. 2006 Spring; 4(2), 75-8.

INAYAT KHAN, H. (1995). La música de la vida. Madrid, Mandala Ediciones.

KEARNEY, M. \& WEININGER, R. (2012). Care of the soul. En: Cobb, M.R., Puchlasky, C.M. \& RUMBOLD, B. Oxford Textbook of Spirituality in Healthcare. Oxford University Press. DOI: 10.1093/med/9780199571390.001.0001.

MAGILL, L. (2009). The spiritual meaning of pre-loss music therapy to be reaved caregivers of advanced cancer patients. Palliative and Supportive Care, 7, 97108.

MATEU, R. (2001). El lugar del silencio en el proceso de comunicación. Tesis doctoral. Universitat de Lleida. Departament de Filologia Clàssica, Francesa i Hispànica. ISBN: 8468835560. Recuperado el 26 de abril de 2015 de: http://hdl.handle. net/10803/8173.

MCCLEAN, S., BUNT, L. \& DAYKIN, N. (2012). The Healing and Spiritual Properties of Music Therapy at a Cancer Care Center. The journal of alternative and complementary medicine, Vol. Volume 18, Number 4, 402-407.

Nhat Hanh, T. (2007). El milagro de mindfulness. Barcelona, Oniro.

O'CALlaghan, C. (1996). Lyrical Themes in Songs Written by Palliative Care Patients. J Music Ther, 33 (2): 74-92. DOI: 10.1093/jmt/33.2.74.

O'CALlaghan, C. (2009). Objectivist and Constructivist Music Therapy Research in Oncology and Palliative Care: An Overview and Reflection. Music and Medicine, 1: 41. DOI: 10.1177/1943862109337135. 
PUYVELDE, M. V. et al. (2010). Tonal synchrony in mother-infant interaction based on harmonic and pentatonic series. Infant Behavior and Development, DOI: 10.1016/j.infbeh.2010.04.003.

Real Academia Española. (2014). Diccionario de la Real Academia de la Lengua Española (23a . Ed.). Recuperado el 26 de abril de 2015 de http//: www.rae.es

REIG-FERRER, A., FERRER-CASCALES, R., FERNÁNDEZ-PASCUAL, M.D., ALBADALEJO-BLÁZQUEZ, N. \& PRIEGO VALLADARES, M. (2015). Evaluación del bienestar espiritual en pacientes en cuidados paliativos. Medicina Paliativa, 22(2), 60-80.

RENZ, M, MAO, M.S., BUECHE, D., CERNY, T. \& STRASSER, F. (2013). Dying is a transition. Am J Hosp Palliat Care., May; 30(3):283-90. DOI: 10.1177/1049909112451868. Epub 2012 Jul 12.

RENZ, M. et al. (2015). Spiritual experiences of transcendence in patients with advanced cancer. American Journal of Hospice \& Palliative Medicine, Vol. 32(2), 178-188.

Rimpoché, S. (2006). El libro tibetano de la vida y de la muerte. Barcelona, Ediciones Urano.

SERRA, M. (2013). Comparación del efecto de una intervención con musicoterapia para mujeres con cáncer de mama durante la sesión de quimioterapia: un análisis cuantitativo y cualitativo. Tesis doctoral. FPCEE Blanquerna. Universitat Ramon LLull. Barcelona.

Serra, M., Juan. E. \& Rufino, M. (2008). El río de la vida. Una intervención en cuidados paliativos. Actas del II Congreso Nacional de Musicoterapia, 87-88. Zaragoza, Estudio de Palabras Editorial.

SERRA, M., GIL, O.T. \& DE LUIS, V. (2012). Efectos de la musicoterapia en la percepción del dolor en una UCP hospitalaria. Póster presentado en el IX Congreso Nacional de la Sociedad Española de Cuidados Paliativos (SECPAL). Badajoz, 9-11 de mayo de 2012.

SERRA, M., DE LUIS, V. \& VALLS, J. (2014). Evaluación de un programa de musicoterapia en una unidad de cuidados paliativos. La perspectiva de los cuidadores. Medicina Paliativa 06/2014. DOI: 10.1016/j.medipa.2014.02.002.

STEVENS, C. (2014). La música como medicina. Barcelona, Ediciones Urano.

TAMPLIN, J.(2006). Song Collage Technique:ANewApproachtoSongwriting. Nordic Journal of Music Therapy, 15: 2, 177 - 190. DOI: 10.1080/08098130609478164.

TVE. Documentos TV: El último viaje (9.12.2008). Recuperado el 26 de abril de 2015 de: http://www.rtve.es/alacarta/videos/documentos-tv/documentos-tv-ultimo-viaje $/ 360268 /$ ?s $1=$ noticias\&s $2=$ documentales\&s3\#

VAN LOMMEL, P. (2012). Consciencia más allá de la vida. Girona, Ediciones Atalanta.

World Federation of Music Therapy (2011). (Recuperado el 26 de abril de 2015 de: http://www.wfmt.info/WFMT/FAQ_Music_Therapy.html 
WÜNSCH, W. (1995). La formación del hombre a través de la música. La enseñanza de la música en la Escuela Waldorf. Valldoreix, Cuadernos Pau de Damasc.

\section{Notas al pie}

1. Licenciada en filosofía y letras. musicoterapeuta. doctora en psicología (tesis doctoral sobre musicoterapia y cáncer). especializada en ámbito clínico, oncología y cuidados paliativos. ha colaborado y trabajado como musicoterapeuta en diferentes hospitales y asociaciones de pacientes. es profesora en varios másters de musicoterapia, artes creativas, enfermería oncológica y paliativa, y medina paliativa. Actualmente reside en Barcelona. 